\title{
ENGAJAMENTO DO PROFESSOR EM HOME-OFFICE DEVIDO AO \\ SÚBITO ISOLAMENTO PROVOCADO PELA PANDÊMICA DO \\ COVID-19
}

Gabriela Azevedo-gabriela.azevedo@verace.com.br

Instituto Mauá de Tecnologia - Escola de Engenharia Mauá

Praça Mauá, 01

09580-900 - São Caetano do Sul - SP

Octavio Mattasoglio Neto - omattasoglio@maua.br

Instituto Mauá de Tecnologia - Escola de Engenharia Mauá

Praça Mauá, 01

09580-900 - São Caetano do Sul - SP

Thais Bagatim Fonseca - thais.fonseca@maua.br*

Instituto Mauá de Tecnologia - Escola de Engenharia Mauá

Praça Mauá, 01

09580-900 - São Caetano do Sul - SP

Resumo: Este artigo apresenta uma proposta de acolhimento de professores em trabalho em home-office devido o confinamento social provocado pela pandemia do Covid-19. Esse isolamento provoca um desconforto em muitos professores pelo fato de estarem em suas casas afastados do convívio profissional presencial. Para minimizar os efeitos desse isolamento uma escola criou um encontro semanal online, denominado "Encontro das Canecas", para discutir temas relacionados ao bem-estar do professor, a aspectos técnicos da mediação das aulas pela tecnologia e atitudes sócio-comportamentais. Esses encontros foram gravados o que permitiu uma análise dos temas abordados. Neste artigo será apresentado a análise dos dados das gravações além de dados de uma pesquisa realizada com os professores após o fechamento do ciclo de encontros do primeiro semestre. A dinâmica adotada e os resultados podem ajudar outras instituições de ensino de engenharia a promover encontros deste tipo, melhorando as condições de trabalho online pela qual passamos neste momento.

Palavras-chave: Engajamento do professor. Acolhimento. Home-office. Pandemia Covid-19. 


\section{INTRODUÇÃO}

O ano de 2020 foi um ano atípico com a explosão da pandemia da Covid-19 o que levou todas as escolas do Brasil a interromperem suas atividades presenciais, voltando-se para o trabalho mediado pela tecnologia. Essa nova realidade levou à uma corrida por tecnologias e estratégias de trabalho remoto para atender à demanda de promover a aprendizagem nas mais diversas áreas do conhecimento.

Nos cursos de engenharia há a premissa de que alguns conteúdos devem ser realizados em laboratórios presenciais, como é o caso das aulas de laboratórios de Física e Química (MEC, 2019). Apesar dessa diretriz, a contingência gerada pela pandemia fez com que todas as disciplinas tivessem que ser adaptadas para serem oferecidas a distância.

Todas essas mudanças nas estratégias e até mesmo na forma de avaliação fez com que os professores passassem a realizar um trabalho hercúleo de transformação dos conteúdos de suas disciplinas para o trabalho mediado pela tecnologia. No que diz respeito ao suporte técnico para a realização dessa mudança, já há muito tempo eles estão à disposição de professores e instituições de ensino, que utilizam ambientes virtuais de aprendizagem - AVA - ou para promoverem cursos a distância ou como ferramentas de apoio ao ensino presencial.

Por sua vez houve uma outra mudança mais radical no trabalho realizado pelo professore que foi o fato de ele estar em trabalho domiciliar, ou como é comumente conhecido em homeoffice. Essa nova situação colocou os professores frente a uma nova situação, distante fisicamente dos estudantes, dos laboratórios das suas instituições de ensino e do ambiente de trabalho presencial, o que se configurou numa situação inusitada para muitos desses profissionais, tirando-os do modus operandi, que vivenciaram ao longo de toda vida, seja como estudantes, seja como professores.

O isolamento no trabalho domiciliar levou a diversos tipos de respostas dos professores, que logo foram percebidas na instituição cujo caso neste trabalho será relatado e que passou a promover encontros virtuais, nos quais os professores foram acolhidos para conversar sobre temas diversos.

O objetivo deste trabalho é relatar a experiência de acolhimento de professores em trabalho domiciliar decorrente do isolamento consequente da pandemia de COVID-19. Dado o fato de que este cenário de isolamento pode se manter ao longo de um período próximo, discutir formas de acolhimento dos professores é subsídio para se promover uma situação de mais conforto a esses profissionais. O lema "isolado mas não sozinho", foi utilizado no início desse programa, e explicita o objetivo desses encontros. Batizado de "Encontro das canecas", que tem como origem o fato de diversos profissionais estarem à frente do computador com suas canecas com café ou outras bebidas que os apeteçam, o evento se tornou uma referência nos meses de isolamento vividos no primeiro semestre de 2020 e que será aqui relatado.

\section{REFERENCIAL TEÓRICO}

Os professores exercem um papel importante na formação de indivíduos desde a pré-escola até o ensino superior. São agentes facilitadores no processo de aprendizagem, de integração social e inserção no mercado de trabalho. Ao pensarmos as organizações de ensino e professores, ao pensarmos os processos de educação, é comum voltarmos o olhar para o aluno e procurarmos oferecer a ele todos os recursos que são necessários ao seu desenvolvimento. No entanto, há um aspecto que nem sempre recebe a mesma atenção, mas que tem tanto impacto para o desenvolvimento do aluno quanto os demais: o bem-estar do professor. 
De acordo com Jennings \& Greenberg (2009), desenvolver o professor em seus aspectos socioemocionais e promover sua saúde e bem-estar, impacta positivamente na relação com o aluno. Um crescente aumento de evidências que revelam que o bom vínculo exerce um papel importante para a conexão do aluno com a instituição de ensino, para os resultados acadêmicos e na retenção tanto de alunos como de professores.

Para Greenberg ${ }^{2}$, este desenvolvimento dos professores pode ocorrer por meio de ações de prevenção com foco na redução de estresse, percepção de emoções, atenção plena e compaixão. São intervenções que evidenciam a importância da educação socioemocional para adultos.

Se estas são diretrizes importantes na educação em um cenário de normalidade, é inegável que o olhar para estes aspectos em momentos de crise deva ser ainda mais cuidadoso.

No período de pandemia provocado pelo Covid-19, foi mandatório transformar o ensino presencial em ensino mediado pela tecnologia. Com isso, além das adversidades corriqueiras enfrentadas pelo corpo docente no cotidiano educacional, ele foi confrontado com novas demandas ainda mais desafiadoras. De acordo com pesquisa realizada por Hamilton \& $\mathrm{Col}^{3}$, dentre os aspectos citados pelos professores como dificuldades enfrentadas neste período, estavam a preocupação em manter o engajamento de todos nas vídeo-aulas, a dificuldade de perceber o estado emocional do aluno, a falta de troca e networking entre os professores.

Já em pesquisa realizada pelo Instituto Península ${ }^{4}$ no período de 23 de março a 04 de abril, início do isolamento social, revelou que dos 2,4 mil professores entrevistados, $90 \%$ estavam totalmente preocupados com a situação atual e percebiam efeitos em sua saúde emocional.

Frente a estes dados, fica claro que Covid-19 gerou não só a transformação em sala de aula, como provocou importantes impactos psicológicos e no bem-estar físico dos professores. Assim, ter ações para mitigar o estresse vivido nessa fase se torna essencial.

\section{MÉTODO DE PESQUISA}

Cada um dos "Encontro das canecas" foi gravado o que permitiu a retomada dos encontros e para análise dos conteúdos abordados e interação que foi realizada com os participantes. Essas gravações serviram como subsídio para uma síntese de cada encontro, constituindo material de feedback aos professores, no encontro de final de semestre. Essa síntese é o material de análise deste artigo.

Além das gravações, foi realizada uma pesquisa utilizando-se um questionário que foi distribuído de forma online a todos os professores da escola. Esse questionário tinha o objetivo de levantar a percepção dos professores sobre o programa "Encontro das canecas", sendo que também se buscou informação sobre os encontros mais ou menos relevantes, além de se levantar sugestões para eventos futuros.

\section{DADOS E RESULTADOS}

O "Encontro das canecas" foram realizados semanalmente, em dias variados da semana de modo a possibilitar que professores que tivessem impedimento num determinado dia da semana, por compromissos outros, pudessem participar em semanas subsequentes. Dado o fato de que o programa foi criado ao longo do semestre sem a possibilidade de um planejamento prévio, os temas foram escolhidos ao longo do tempo, à medida que necessidades surgissem.

\subsection{A parceria entre a Academia de Professores e Academia de Talentos}

A escola em questão tem dois órgãos de apoio à reitoria que se uniram na tarefa de promover o Encontro das Canecas. A Academia de Professores é um desses órgão e tem a 
responsabilidade de promover a formação continuada dos professores da escola. A Academia de Talentos é o órgão responsável pela orientação ao apoio profissional aos estudantes.

No trabalho colaborativo desenvolvidos, os objetivos dos encontros, temas, interlocutores e critérios de avaliação foram discutidos pelos profissionais desses dois órgãos, sendo que alguns dos encontros foram conduzidos por esses profissionais. Para alguns outros encontros, foram convidados profissionais de áreas específicas, como fonoaudiólogo e professores de Educação Física, que conduziram temas específicos.

\subsection{Temas e gênese dos temas do "Encontro das canecas"}

No primeiro semestre foram realizados nove encontros cujos temas estão indicados no Quadro 1.

Quadro 1 - Programação do "Encontro das canecas" realizados no 1o semestre de 2020.

\begin{tabular}{|l|l|}
\hline Data do evento & \multicolumn{1}{c|}{ Título do evento } \\
\hline 15.04 .2020 & O Aluno em casa: Isolado mas não sozinho \\
\hline 23.04 .2020 & Concentração e Produtividade \\
\hline 04.05 .2020 & Atividades extraclasse para o estudante: quantidade e variedade \\
\hline 11.05 .2020 & Bem-estar emocional do professor \\
\hline 19.05 .2020 & Bem-estar físico e uso da voz \\
\hline 27.05 .2020 & Bem-estar físico: Cuidados com o corpo \\
\hline 04.06 .2020 & Experiências de avaliação no Moodlerooms \\
\hline 12.06 .2020 & Aulas presenciais ou remotas: Qual é a melhor estratégia? \\
\hline 22.06 .2020 & Insights das Canecas \\
\hline
\end{tabular}

Observa-se no Quadro 1 que se tem temas técnicos relacionados ao trabalho mediado pela tecnologia, temas relacionados ao bem-estar dos professores e temas relacionados ao relacionamento interpessoal. No encontro final foi de feedback aos professores, e foi conduzido pelos profissionais da Academia de Professores e Academia de Talentos da escola.

\section{3 - Observação de 03 pontos focais a partir das gravações dos encontros}

Considerando os três grandes temas de atividades - técnicos, bem-estar dos professores, relacionamento interpessoal - foi extraído das gravações os principais elementos que foram trazidos pelos participantes. Esses conteúdos estão indicados no Quadro 2.

\section{Quadro 2-Grandes temas, e extrato da análise de dados}

\begin{tabular}{|l|l|}
\hline Aspectos Técnicos & Adversidades Encontradas \\
& - Sobre o aluno - Dificuldade de gerenciamento das horas. \\
& - Como qualificar o nível das questões online? \\
& Organização. Encontrar a melhor forma de disponibilizar o \\
conteúdo didático dentro da plataforma. \\
Desafios de alunos e professores no retorno presencial - \\
Sentimento de frustração pelos com bons resultados com as aulas \\
remotas. \\
Reestruturação de disciplinas - Inovação.
\end{tabular}


- Atividades extraclasse: quantidade variedade

- Aulas presenciais ou remotas: Qual é a melhor estratégia? Experiências de avaliação no Moodlerooms

\section{Sócio}

Comportamentais

- O aluno em casa - Isolado mas não sozinhos

- Concentração e Produtividade
- Necessidade de novas vivências online, para manter o aluno vinculado.

- Criar estratégias para que discutam e trabalhem durante a aula.

- Ferramentas tecnológicas - Estar atentos às opções disponibilizadas.

- Confiança - Necessidade de um acordo entre professor e alunos. Quanto melhor detalhada as orientações, melhor o resultado.

\section{Resultados}

- Virtudes das tarefas na forma síncrona - Revisão de atividades compartilhadas com toda a classe e divisão em grupos - tarefas e seminários.

- Aulas e Atividades Remotas - Possibilidade de cobranças dos professores aos alunos - escalonadas e frequentes num mesmo projeto.

- Organizar a avalição demanda tempo mas ajuda na correção automática em turmas grandes.

- Feedback do professor nas avaliações, valorizada pelos estudantes.

- Presença de flexibilidade. Mesclar atividades síncronas com as assíncronas.

- Sintonia com a tecnologia para promover a aprendizagem.

\section{Adversidades Encontradas}

- Necessidade de adaptação material presencial para modelo mediado pela tecnologia.

- Estratégia em sala - vídeo gravado prévio ou gravar a aula?.

- Percepção do engajamento - principais desafios enfrentados e recursos utilizados.

- Aulas Remotas - Os alunos presentes, estão presentes?

- Aspectos emocionais - "a massa silenciosa"

- Dificuldades de estudar em casa, organização de tarefas e prioridades. Gestão do tempo.

- Crítica dos alunos referente ao aumento de demanda, se sentem sobrecarregados com muitas tarefas.

- Dificuldade de concentração, dispersões em casa, divisão de espaços e internet com a família.

- Reflexos emocionais que o isolamento pode trazer: falta de motivação, engajamento, irritabilidade e ansiedade.

\section{Resultados}

- Acolhimento permanente durante a pandemia.

- Acesso non-stop via tecnologia

- Alunos conseguem tirar mais dúvidas durante a aula e aproveitar melhor a monitoria.

- Modelo híbrido alavanca o melhor rendimento 


\begin{tabular}{|c|c|}
\hline & $\begin{array}{l}\text { - Necessidade dos professores disporem de maior flexibilidade e } \\
\text { prazos. Cobranças menores, ter um ponto de equilíbrio. } \\
\text { - Espaço para o aluno falar sobre as necessidades, sugestões e } \\
\text { dificuldades encontradas. } \\
\text { - Escuta ativa. Empatia. }\end{array}$ \\
\hline $\begin{array}{l}\text { Bem-estar } \\
\text { emocional do } \\
\text { Professor } \\
\text { Bem-estar } \\
\text { físico e o uso } \\
\text { da voz } \\
\text { Bem-estar } \\
\text { Físico: } \\
\text { Cuidados com } \\
\text { o Corpo }\end{array}$ & $\begin{array}{l}\text { Adversidades Encontradas } \\
\text { - Percepções e sensações do professor durante o isolamento, } \\
\text { dificuldades de adaptação para aplicação de atividades virtuais. } \\
\text { - Alterações na qualidade do sono, alimentação e irritabilidade. } \\
\text { - Desgaste diante das aulas e reuniões virtuais, exigindo uma } \\
\text { atenção maior, causando um cansaço mental e estafa. } \\
\text { - Aumento de sedentarismo durante o período de confinamento. } \\
\text { - Musculatura tensa. } \\
\text { - Desconfortos com a voz (voz mais fraca, rouquidão, dor de } \\
\text { garganta). } \\
\text { - Equipamentos inadequados. } \\
\text { Resultados } \\
\text { - Ficar atento aos sinais. Letargia, angústia, depressão, insônia e } \\
\text { - Mansiedade. Buscar ajuda quando necessário. } \\
\text { - Pratica uma rotina social virtual (socialização) } \\
\text { - Estabelecer uma rotina, disciplina. } \\
\text { - Exercícios de alongamento - Automassagem. } \\
\text { - Alimentação, respiração e hidratação adequadas. } \\
\text { - Pausas durante o trabalho, não permanecer longos períodos } \\
\text { - Pentado. } \\
\text { - Espaço confortável, altura do notebook/computador. Distância } \\
\text { entre pessoa e equipamento. }\end{array}$ \\
\hline
\end{tabular}

Fonte: Os autores

\subsection{Resultados da pesquisa realizada com os professores}

A pesquisa realizada com professores no período de 4 a 6 de agosto de 2020, contou com 20 respondentes. $\mathrm{O}$ resultado obtido evidenciou que a maiores ganhos foram para os aspectos técnicos abordados nos encontros. Enquanto temas relacionados ao bem-estar emocional e físico despertaram interesse menor (). De acordo com os respondentes, os encontros contribuíram menos para a melhoria bem-estar físico dos professores (). 
Figura 1 - Porcentagem de participação dos respondentes nos Encontros das Canecas

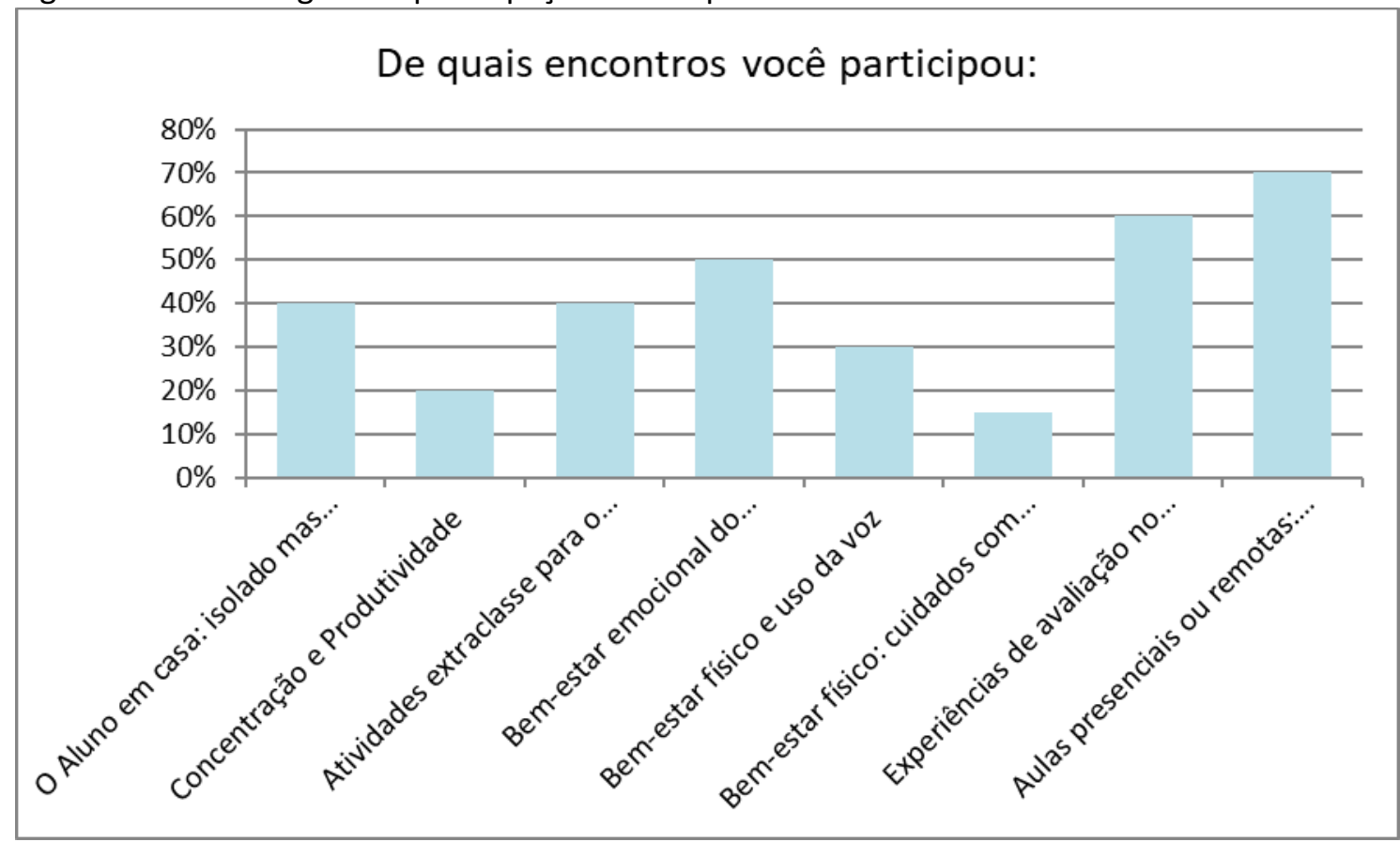

Fonte: Os autores

Figura 2 - Relevância dos encontros

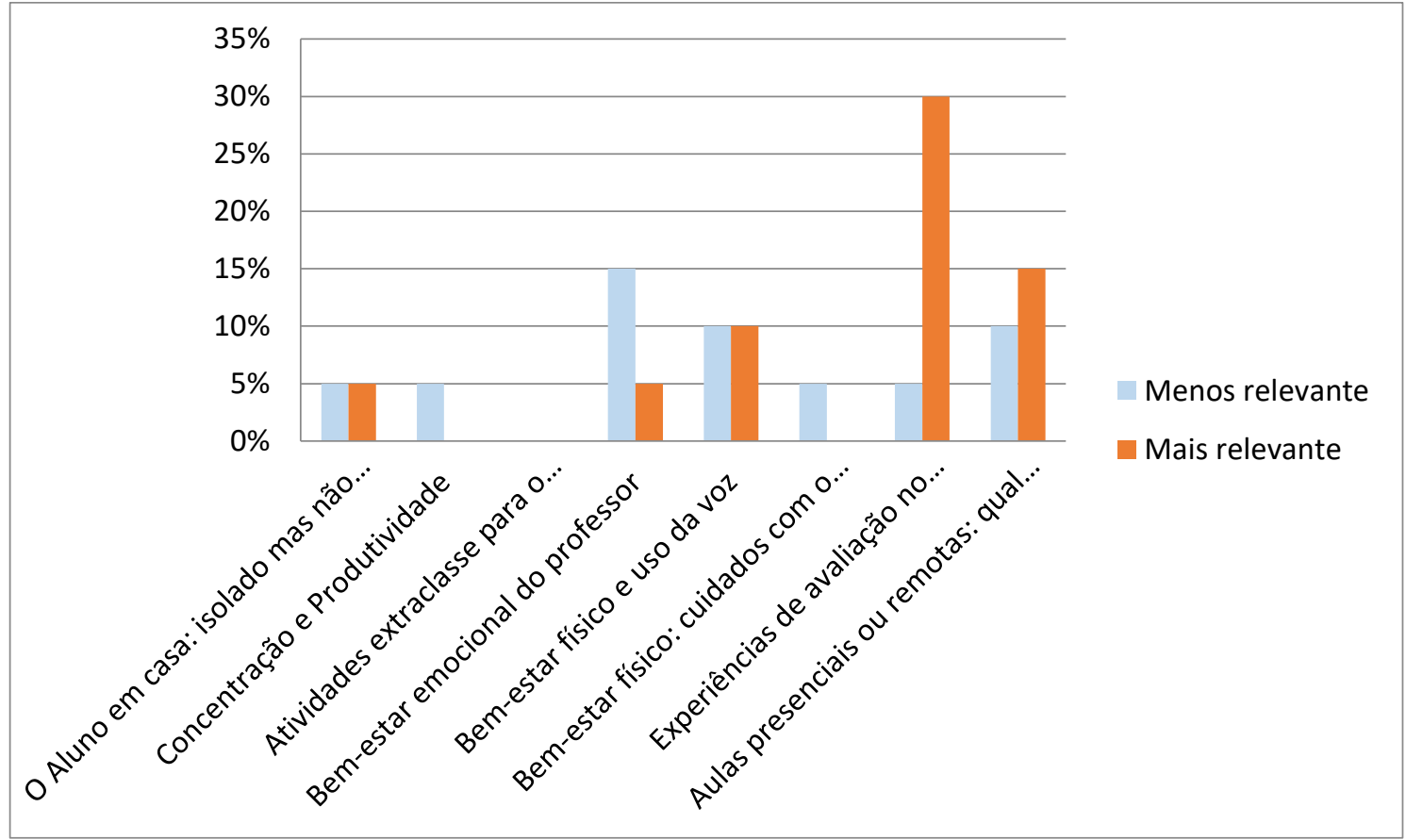

Fonte: Os autores 
Figura 3 - Melhoria do bem-estar emocional

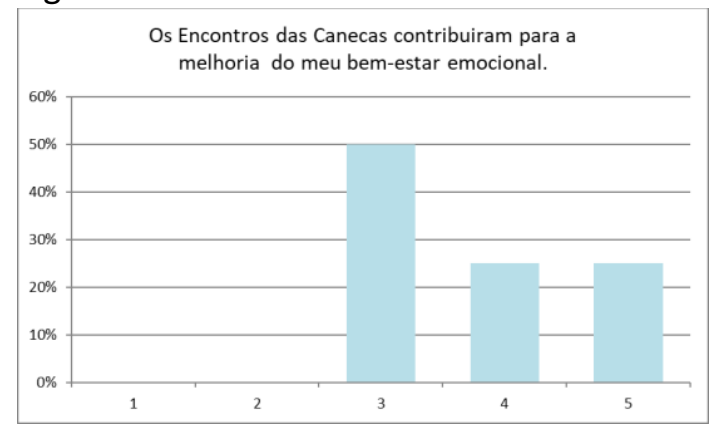

Fonte: Os autores
Figura 4 - Melhoria do bem-estar físico

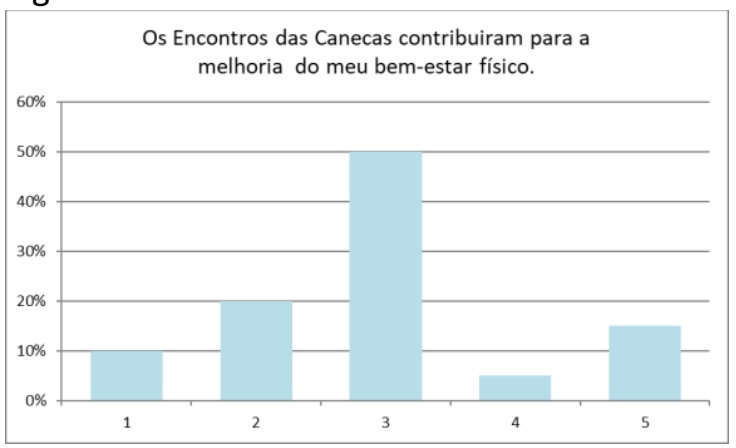

Fonte: Os autores

Figura 5 - Melhoria do conhecimento sobre ferramentas de educação mediada pela tecnologia

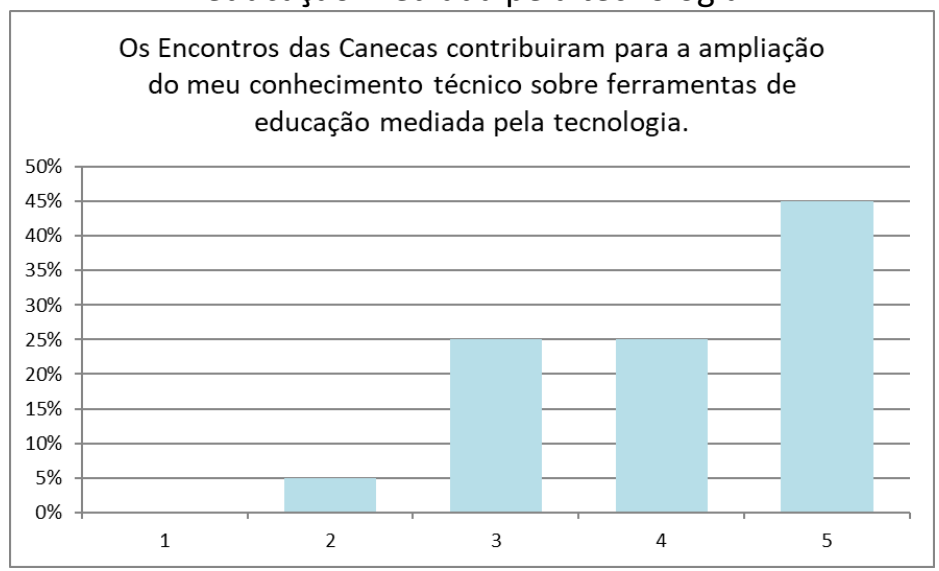

Fonte: Os autores

\section{CONSIDERAÇÕES FINAIS}

O objetivo deste trabalho era de apresentar o Encontro das Canecas e os resultados alcançados neste projeto que foi criado pela necessidade de aproximar os professores da escola e do grupo de professores no momento de isolamento social decorrente da pandemia do COVID-19.

Os resultados indicam uma participação espontânea e forte dos professores, que enriqueceram a discussão dos diversos temas. Os temas relacionados aos aspectos técnicos foram os considerados como os mais relevantes pelos respondentes. Por sua vez, os encontros relacionados com o bem-estar emocional foram mais valorizados do que os encontros relacionados ao bem-estar físico.

De modo geral o "Encontro das Canecas" foi considerado uma experiência positiva pelos respondentes. A decisão da escola é continuar com esse encontro no próximo semestre, de modo a manter o engajamento dos professores.

\section{Agradecimentos}

A todos os professores e profissionais que experiência do Encontro das Canecas e compartilharam experiências e percepções com os colegas. 


\title{
REFERÊNCIAS
}

GREENBERG M. \& JENNINGS P. (2009), The Prosocial Classroom: Teacher Social and Emotional Competence in relation to student and classroom outcomes in Review of Educational Research, 79, 491-525.

GREENBERG M. Adult SEL: fully Measuring the Impact of supporting teacher. Disponível em: https://casel.org/adult-sel-fully-measuring-the-impact-of-supporting-teachers/

Acesso em: 18/07/2020

HAMILTON L S, KAUFMAN J H, DILIBERTI M, Teaching and leading through a pandemic in Insights from American Educators Panels Spring - Disponível em: https://www.rand.org/pubs/research_reports/RRA168-2.html. Acesso em 18/07/2020

INSTITUTO PENÍNSULA - Neste momento tão atípico e incerto como estão nossos mais de 2,2 milhões de professores? Disponível em: https://institutopeninsula.org.br/como-estao-osprofessores-neste-momento-de-crise/. Acesso em 18/07/2020

MEC, Ministério da Educação. Conselho Nacional de Educação. Câmara de Ensino Superior. Resolução CNE/CES n ${ }^{\circ}$ 2, de 24 de abril de 2019Diretrizes Curriculares Nacionais do Curso de Graduação em Engenharia, 2019.

\section{TEACHER ENGAGEMENT IN HOME-OFFICE DUE TO THE SUDDEN INSULATION CAUSED BY THE PANDEMIC OF COVID-19}

\begin{abstract}
This article presents a proposal for the engagement of teachers who are working at home-office due to the social confinement caused by the Covid-19 pandemic. This isolation causes discomfort in many teachers because they are at home, away from face-to-face professional life. To minimize the effects of this isolation, a school created a weekly online meeting, called "Encontro das Canecas", to discuss topics related to the teacher's well-being, to technical aspects of mediation of classes by technology and socio-behavioral attitudes. These meetings were recorded, which allowed an analysis of the topics covered. In this article will be presented the analysis of the data of the recordings in addition to data from a survey carried out with the teachers after the closing of the cycle of meetings of the first semester. The dynamics adopted and the results can help other engineering education institutions to promote meetings of this type, improving the online working conditions that we are currently experiencing.
\end{abstract}

Keywords: Teacher engagement. Reception. Home-office. Covid-19 Pandemic. 